\title{
Effects of Sodium Sulfate and Sodium Chloride for Sonochemical Degradation on 1,4-benzoquinone and Hydroquinone in Aqueous Solution
}

\author{
Md. Helal Uddin* \\ Department of Applied Chemistry and Chemical Engineering, Faculty of Applied Science and Technology, \\ Islamic University, Kushtia-7003, Bangladesh \\ Kenji Okitsu \\ Department of Materials Science, Graduate School of Engineering, Osaka Prefecture University, \\ 1-1 Gakuen-cho, Naka-ku, Sakai, Osaka 599-8531, Japan
}

\begin{abstract}
1,4-benzoquinone, with the molecular formula $\mathrm{C}_{6} \mathrm{H}_{4} \mathrm{O}_{2}$, is generally known as a para-quinone. It is a six-member ring compound with an oxidized derivative known as 1,4-hydroquinone, which is a bright yellow crystal that has an irritating odour. On the other hand, hydroquinone, also known as benzene-1,4-diol, has the chemical formula $\mathrm{C}_{6} \mathrm{H}_{4}(\mathrm{OH})_{2}$. It looks like a white granular solid. Quinone is generally used as a precursor to hydroquinone. The skeletal muscle relaxant, ganglion blocking agent, benzoquinonium, is made from benzoquinone. It is utilized to suppress double-bond migrations during olefin metathesis reactions. 1,4-benzoquinone is also used in the synthesis of Bromodol, while hydroquinone is the main ingredient in black-and-white photographic developers such as film and paper developers, where it diminishes the silver halide to elemental silver. There are various other uses related to this diminishing power. As a polymerization inhibitor, hydroquinone prevents the polymerization of methyl methacrylate, acrylic acid, etc. Studies have demonstrated the various effects of $\mathrm{Na}_{2} \mathrm{SO}_{4}$ and $\mathrm{NaCl}$ on the sonochemical degradation of 1,4-benzoquinone and hydroquinone using a $200-\mathrm{kHz}$ sonicator. The highest degradation rate was obtained in the presence of $0.433 \mathrm{M} \mathrm{Na} \mathrm{SO}_{4}$ for 1,4-benzoquinone. After 30 minutes of ultrasonic irradiation, the total concentration of 1,4-benzoquinone decreased to $99 \%$ in the presence $0.433 \mathrm{M} \mathrm{Na}_{2} \mathrm{SO}_{4}$. Without $\mathrm{Na}_{2} \mathrm{SO}_{4}$, the sonochemical degradation rate of 1,4-benzoquinone was 4.5 times higher than that of hydroquinone, whereas in the presence of $0.433 \mathrm{M} \mathrm{Na}_{2} \mathrm{SO}_{4}$ under the same conditions the initial reaction rate of 1,4benzoquinone was increased to become 10.6 times higher than that of hydroquinone. On the other hand, in the presence of $\mathrm{NaCl}$, no effects were observed for the decomposition of hydroquinone but negative effects were clearly observed for the decomposition of 1,4-benzoquinone.
\end{abstract}

Keywords: 1,4-benzoquinone; Hydroquinone; $\mathrm{Na}_{2} \mathrm{SO}_{4}$; $\mathrm{NaCl}$; Sonication

\section{INTRODUCTION}

For the last few decades, Advanced Oxidation Processes (AOPs) such as $\mathrm{O}_{3}$, UV with $\mathrm{H}_{2} \mathrm{O}_{2}$, UV with $\mathrm{O}_{3}, \mathrm{Fe}^{2+}$ with $\mathrm{H}_{2} \mathrm{O}_{2}$ and UV with $\mathrm{O}_{3}$ and $\mathrm{H}_{2} \mathrm{O}_{2}$ have become visible as undertaking technologies for the degradation of uncooperative organic hazardous wastes (Rosenfeldt et al. 2004; Spanggord et al. $2000 \&$ Anotai et al. 2006). AOPs produce $\cdot \mathrm{OH}$ radicals which has redox potential $2.8 \mathrm{~V}$ vs. Normal Hydrogen Electrode (NHE) are strongly reactive for organic pollutants. At present, applications of new AOPs with $\mathrm{SO}_{4}{ }^{2-}$ radicals which are formed via reaction of $\mathrm{OH}$ radicals with sulfate ions has been investigated because $\mathrm{SO}_{4}^{2-}$ radical anion $\left(E^{0}=2.5-3.1 \mathrm{~V}\right.$ vs. NHE) also possess high oxidation potential. There are various researches have been brought out by the use of $\mathrm{SO}_{4}^{2-}$ radicals for the decomposition of a variety of organic pollutants (Waldemer et al. 2007; Fernandez et al. 2004; Bandala et al. 2007 \& Hori et al. 2005).

Sonochemical degradation method is a promising one because maximum reaction conditions including pyrolysis and radical reactions are generated via the formation of cavitation bubbles with high temperatures and pressures.
As for sonolysis in aqueous solutions, hydroxyl radicals are produced through the expeditious collapse of cavitation bubbles (Makino et al. 1983 \& Riesz et al. 1985). So that, the sonochemical degradation method has raised a wide attention in environmental applications such as organic pollutants control (Mallakpour et al. 2014 \& Saccani et al. 2014), biological hydrogen production (Guo et al. 2011 \& Yang et al. 2012), and excess sludge reduction (He et al. 2011; Yang et al. $2013 \&$ Guo et al. 2013). Sonochemical degradation of phenol and phenolic compounds has been investigated by several researchers and investigated some intermediates such as hydroquinone, benzoquinone, catechol (Lim et al. 2014; Jyothi et al. 2014; Rokhina et al. 2013; Wang et al. 2013; Verma et al. 2013; Sakakura \& Mitsuo 2012; Joseph et al. 2011; Zhang et al. 2011; Torres-Palma et al. 2010; Berlan et al. 1994; Entezari et al. 2003; Petrier et al. 1994; Dükkanc1 et al. 2006 \& Serpone et al. 1993). These compounds further decomposed into more hydrophilic compounds that is formic and oxalic acid (Dukkanc et al. 2006 \& Yim et al. 2003).

Although there are many reports for sonochemical degradation of phenol and phenolic compounds (Lim et al. 2014; Jyothi et al. 2014; Rokhina et al. 2013; Wang et al. 
2013; Verma et al. 2013; Sakakura \& Mitsuo 2012; Joseph et al. 2011; Zhang et al. 2011, and Torres-Palma et al. 2010), to the best of our knowledge, sonochemical decomposition of 1,4-benzoquinone and hydroquinone under argon gas pressure is not reported.

In this study, we performed the sonchemical degradation of 1,4-benzoquinone and hydroquinone in an aqueous solution at a frequency of $200 \mathrm{kHz}$. The lack of the research is we have performed 30 minutes of experiment and used only two inorganic salts. 1,4-benzoquinone provide an influence to both powerful mineral acids and alkali, which phenomenon condensation and decomposition of the composite. Its acute toxicity (oral LD50: $130 \mathrm{mg} / \mathrm{kg}$ body weight for rats) (Patnaik 2007). On the other hand acute toxicity of hydroquinone (oral LD50 value for both sexes combined was $>375 \mathrm{mg} / \mathrm{kg}$ ) (Topping et al. 2007). As electron acceptor benzoquinones perform a vital role in the breathing organisms (Okamura et al. 2000 \& Kawamukai 2002). Consequent to UV irradiation of benzoquinone by-products in aqueous media, hydroxyquinone and oxygen are produced (Leighton et al. 1929; Lente et al. 2004 \& Joschek et al. 1966). The oxidation of diverse quinones to hydroxyquinones was expressed in the research (Spyroudis 2000).

On the other hand, hydroquinone is considered the main potential molecular messengers for semiquinonetype natives in the ignition of complicated polymeric and oligomeric arrangements accommodated in biomass components. Hydroquinone and its outgrowths are strong registered products of the ignition and pyrolysis of frequent types of biomass, as well as tobacco (Visser et al. 1985 and Lee et al. 1999). Consumption of hydroquinone has been displayed to induce choking, oxidizing impression, affected breathing in humans over and above reduced bone marrow and corneal damage in mice (Bilimoria et al. 1975 and Leanderson \& Christer 1992). For all that, the discarding interest with hydroquinone in ignition and pyrolysis is its deterioration to produce persistent, semiquinone-type free radicals and other toxic outgrowths. It is acknowledged that pyrolysis of hydroquinone edges to the construction of p-benzoquinone and phenol (Sakai \& Masayuki 1976 and Khachatryan et al. 2006) over and above a number of other aromatic and polycyclic aromatic hydrocarbon products (Ledesma et al. 2002 and Marsh et al. 2004). In this paper, we analyzed the effects of $\mathrm{Na}_{2} \mathrm{SO}_{4}$ and $\mathrm{NaCl}$ on the sonochemical decomposition of 1,4-benzoquinone and hydroquinone to enhance the rate of degradation. In addition, we also suggested that the degradation mechanism of 1,4benzoquinone and hydroquinone was different from that of other phenolic compounds. $\mathrm{Na}_{2} \mathrm{SO}_{4}$ and $\mathrm{NaCl}$ also known as degrading agent in AOPs. Uddin et al. (2016) published on sonochemical decomposition in presence of inorganic salts corresponded of no effect or slight negative or positive effects.

\section{EXPERIMENTAL SECTION}

1,4-bezoquinone purity $98 \%$, hydroquinone, sodium sulfate (anhydrous) both purity 99\%, and sodium chloride purity 99.5\% was purchased from Wako Pure Chemical Industries, Ltd. Japan. All the chemicals were reagent grade and used after received. Decontaminated water $(18.2 \mathrm{M} \Omega \mathrm{cm}$ resistivity) was prepared from a Millipore Milli-Q Gradient water purification system and was used to prepare all aqueous solutions. Argon (99.999\% purity) was purchased from Osaka Sanso, Japan.

\section{SONOLYSIS}

Ultrasonic generator (Kaijo 4021, Lot no. 1033, MFG. no. $34 \mathrm{C} 3$ ) and a oscillator of $65 \mathrm{~mm}$ inner diameter were used for sonochemical degradation and were control at $200 \mathrm{kHz}$ with an input power of $200 \mathrm{~W}$. The glass vessel with a gross volume of $60 \mathrm{ml}$ sample solution was used for ultrasonic irradiation under argon atmosphere. The vessel had a side arm with a silicon rubber septum for argon gas bubbling and sample extracting (every $0,5,10,20$ and $30 \mathrm{~min}$ ) by the glass syringe $(1 \mathrm{ml})$ without exposing the sample to air.

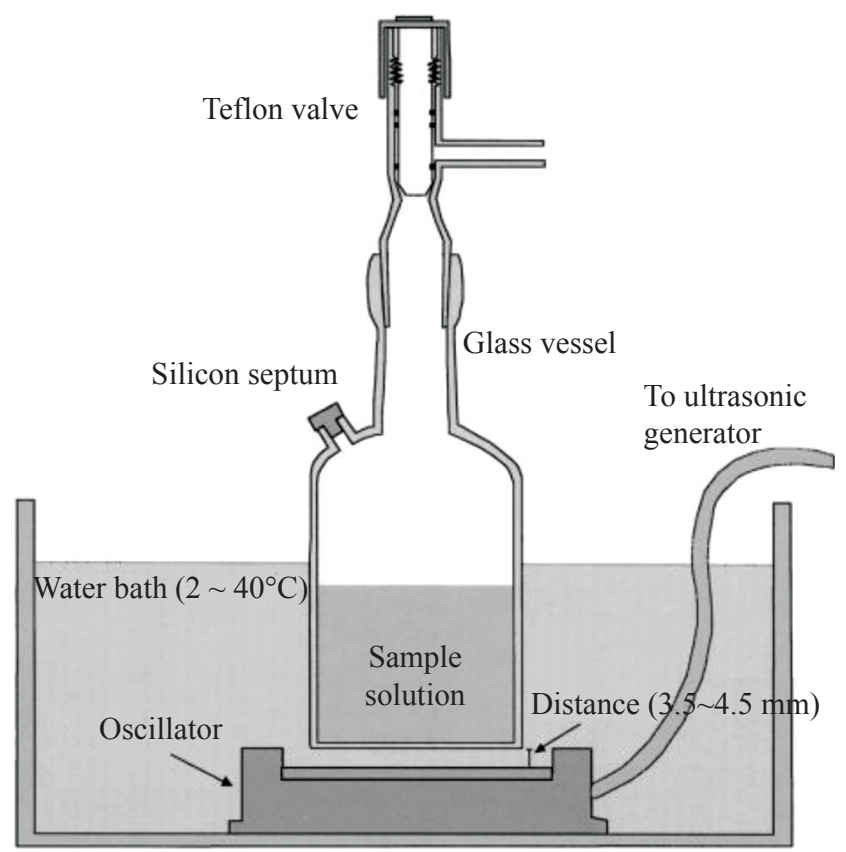

FIGURE 1. The schematic diagram of experimental setup for sonolysis (Okitsu et al. 2002).

The schematic diagram of the experimental setup as shown in Figure 1 was described in the literature (Okitsu et al. 2002). The glass vessel was flat bottomed and $1 \mathrm{~mm}$ thick. The vessel was climb up at a constant position ( $4 \mathrm{~mm}$ from the oscillator). The sonicated solution concentrations were determined with a HPLC. 


\section{CALORIMETRICALLY POWER MEASUREMENT}

When a wave experiences any inequality in the belongings of the channel in which it is propagating, its way of behaving is disturbed. Moderately changes in the way extending over many wavelengths conduct mostly to alter in wave speed and generate direction-the phenomenon of refraction. Sonochemical power usually indicated as the electrical input or output power to and from the generator. Several procedures are available to evaluate the amount of ultrasonic power entered into a sonochemical reaction (Mason 1991). Calorimetric method, that involves computation of the initial rate of a temperature increase produced when a system is illuminated by power ultrasound. This is established on the supposition that almost all the mechanical energy fabricates heat and thus the output power can be procured via calorimetry. In the present experiment, acoustic energy was measured by the calorimetric method.

For one and all system the temperature $(\mathrm{T})$ in the reaction cell was recorded against time ( $\mathrm{t}$ ) at $10 \mathrm{~s}$, intervals, using a thermocouple placed in the reaction vessel. From the $\mathrm{T}$ versus $t$ data, total acoustic power can be calculated using the Equation (1).

$$
\mathrm{Pw}=\mathrm{m} \mathrm{Cp}(\Delta \mathrm{T} / \Delta \mathrm{t})
$$

Where,

$\mathrm{Pw}=$ power $($ Watt $)$,

$\mathrm{m}=$ mass of water used $(100 \mathrm{~g})$,

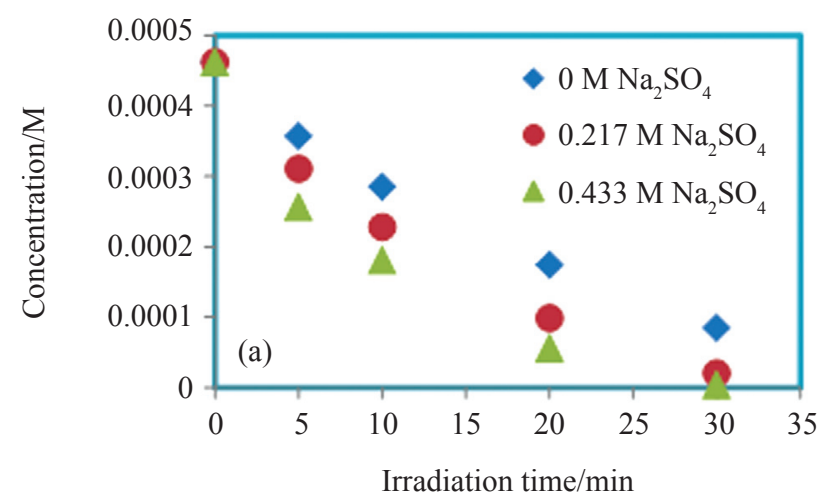

(a)
$\mathrm{Cp}=$ heat capacity of water $\left(4.18 \mathrm{~J} \cdot \mathrm{g}^{-1} \mathrm{~K}^{-1}\right)$,

$\Delta \mathrm{T}=$ temperature rise $\left[(28.2-27.1)=1.1^{\circ} \mathrm{C}\right]$,

$\Delta \mathrm{t}=$ interval of time $(30 \mathrm{~s})$.

Before and after ultrasonic irradiation, the inside reactor cell temperature of water was thermostated at room temperature. Calorimetric power quantifications were carried out three times under the same conditions, and the volume of solution in the reaction vessel was $60 \mathrm{~g}$. The calorimetric power was input in the cell was around $15 \mathrm{~W}$.

\section{RESULTS AND DISCUSSION}

Throughout the sonolysis of water, it is popular that acoustic cavitation originates highly reactive primary radicals such as $\mathrm{OH}$ and $\mathrm{H}$ due to the thermal decomposition of water as shown in Equation (2) (Ashokkumar et al. 2008 \& 2004). A number of recombination and other reactions (Equations (3)-(4)) occur. The $\mathrm{OH}$ radical is a nonselective oxidant with a high redox potential $(2.8 \mathrm{~V})$, having the power to oxidize most organic pollutants.

$$
\begin{aligned}
& \left.\left.\left.\left.\mathrm{H}_{2} \mathrm{O}()\right)\right)\right)\right) \rightarrow \mathrm{HO} \cdot+\mathrm{H} \cdot \\
& \mathrm{HO} \cdot+\mathrm{H} \cdot \rightarrow \mathrm{H}_{2} \mathrm{O} \\
& \mathrm{HO} \cdot+\mathrm{HO} \cdot \rightarrow \mathrm{H}_{2} \mathrm{O}_{2}
\end{aligned}
$$

where “())))))" refers to sonication.

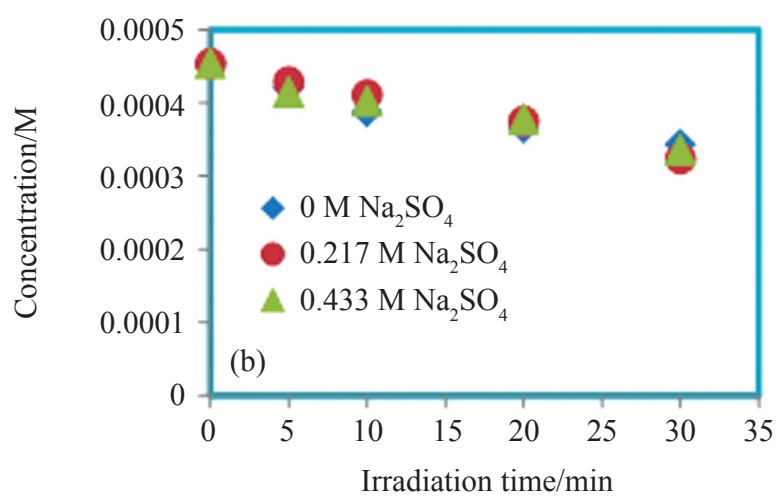

(b)

FIGURE 2. Effects of sonochemical degradation of a) 1,4-benzoquinone and b) hydroquinone in absence and presence of $\mathrm{Na}_{2} \mathrm{SO}_{4}$.

Sonochemical degradation of 1,4-benzoquinone and hydroquinone was inquired into the absence and presence of $\mathrm{Na}_{2} \mathrm{SO}_{4}$ respectively using UV-vis spectrophotometer. Figure 2(a) and (b) show the effects of sonochemical degradation of 1,4-benzoquinone and hydroquinone in the absence and presence of various concentrations of $\mathrm{Na}_{2} \mathrm{SO}_{4}$. Figure 1(a) shows, the initial rate of sonochemical decomposition of 1,4-benzoquinone increased 2.8 times in presence of 0.433 $\mathrm{M} \mathrm{Na}_{2} \mathrm{SO}_{4}$ than in absence of $\mathrm{Na}_{2} \mathrm{SO}_{4}$. In contrast, at same concentration of $\mathrm{Na}_{2} \mathrm{SO}_{4}$ the sonochemical degradation of hydroquinone was not increased conspicuously as shown in Figure 2(b).
Therefore, to understand the sonochemical degradation mechanism of 1,4-benzoquinone and hydroquinone research was performed in presence of different electrolytes such as $\mathrm{Na}_{2} \mathrm{SO}_{4}$ and $\mathrm{NaCl}$ using HPLC. Figure 2 also shows change in the concentration of phenolic compounds throughout sonication under Ar atmosphere. From Figure 2, it was observed that the degradation rates of 1,4-benzoquinone was strongly affected by the addition of $\mathrm{Na}_{2} \mathrm{SO}_{4}$, on the other hand hydroquinone was slightly affected by the addition of $\mathrm{Na}_{2} \mathrm{SO}_{4}$. After $30 \mathrm{~min}$ ultrasonic irradiation reaction, the total concentration of 1,4-benzozuinone was decreased $99 \%$ in the presence of $0.433 \mathrm{M} \mathrm{Na}_{2} \mathrm{SO}_{4}$. The initial rate of 
1,4-benzoquinone (in presence of $0.433 \mathrm{M} \mathrm{Na}_{2} \mathrm{SO}_{4}$ ) was increased 2.6 times than in the absence of $\mathrm{Na}_{2} \mathrm{SO}_{4}$. On the other study, in the presence of same concentration of $\mathrm{Na}_{2} \mathrm{SO}_{4}$, during sonochemical degradation of hydroquinone the decomposition rate slightly increased. In the presence of 0.433 $\mathrm{M} \mathrm{Na}_{2} \mathrm{SO}_{4}$, after 30 min sonication the total concentration of hydroquinone decreased only $26 \%$, whereas in the absence of

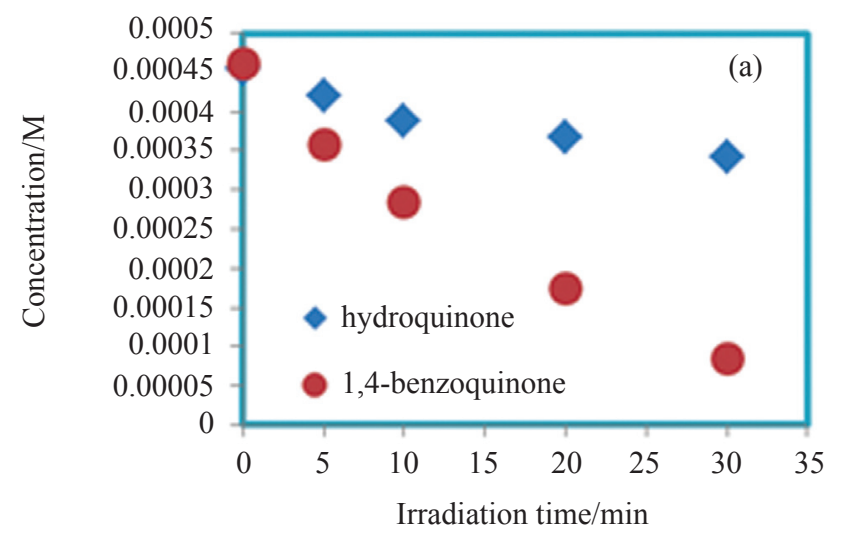

(a)
$\mathrm{Na}_{2} \mathrm{SO}_{4}$ it was $24 \%$. From Figure 3 experimentally observed in absence and presence of $\mathrm{Na}_{2} \mathrm{SO}_{4}$ the rates of sonochemical decomposition of 1,4-benzoquinone and hydroquinone were different. Figure 2 shows the comparison on time dependence of sonochemical degradation of 1,4-benzoquinone and hydroquinone in absence and presence of $\mathrm{Na}_{2} \mathrm{SO}_{4}$.

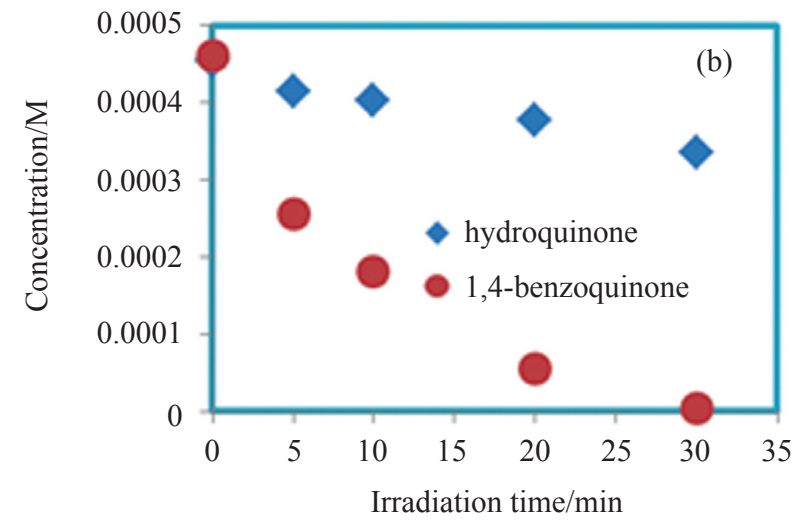

(b)

FIGURE 3. Comparison on time dependence of sonochemical decomposition of 1,4-benzoquinone and hydroquinone in the a) absence, b) presence of $\mathrm{Na}_{2} \mathrm{SO}_{4}$.

Figure 3 clearly shows that, the sonochemical degradation rate of 1,4-benzoquinone in the absence of $\mathrm{Na}_{2} \mathrm{SO}_{4}$ was 4.5 times higher than hydroquinone, whereas in presence of 0.433 $\mathrm{M} \mathrm{Na}_{2} \mathrm{SO}_{4}$ at same condition the 1,4-benzoquinone reaction rate was increased 10.6 times higher than hydroquinone. The pKa values of 1,4-benzoquinone and hydroquinone were 4.2 and 4.0 respectively. In the particular case of 1,4benzoquinone that reported in a cyclic voltammetric study of the aqueous electrochemistry system. The common shape of the potential-pH diagrams for the other quinones were similar to that of 1,4-benzoquinone, but not hydroxyquinone (Bailey et al. 1985).

We also explored the effects of $\mathrm{NaCl}$ on the rate of sonochemical decomposition 1,4-benzoquinone and hydroquinone. Even in the case of $\mathrm{NaCl}$, no effect was observed for hydroquinone but clearly observed negative effect for 1,4-benzoquinone sonication as seen in Figure 4.

In the absence of salt, the initial rates of sonochemical degradation 1,4-benzoquinone were faster than those of hydroquinone. It is well known that the hydrophobicity of an organic solute is one of the most important parameters for sonochemical decomposition, because highly hydrophobic compounds tend to concentrate at the gas liquid interface where the concentration of $\mathrm{OH}$ radicals is very high (Henglein et al. 1985). To confirm hydrophobicity of solutes, we measured $\log \mathrm{P}$ of these compounds and found that 1,4benzoquinone $\left(\log \mathrm{P}=0.16^{*}, 0.19\right.$ (Moret et al. 1996) and hydroquinone $(\log \mathrm{P}=0.58 *, 0.59$ (Veith et al. 1979), here, * symbol indicates experimental value.

Nanzai et al. mentioned that aromatic compounds decomposition rate increased with increasing value of $\log \mathrm{P}$
(Nanzai et al. 2008) but present results were contradictory with Nanzai et al. The addition of $\mathrm{Na}_{2} \mathrm{SO}_{4}$ significantly affects the rates of decomposition for 1,4-benzoquinone, but addition of $\mathrm{NaCl}$ does not clearly affect the decomposition rates for 1,4-benzoquinone. Cheng et al. (2010) observed, $\mathrm{NaHCO}_{3}$ and $\mathrm{Na}_{2} \mathrm{SO}_{4}$ are found to reduce the sonochemical rate constants for PFOX $(\mathrm{X}=\mathrm{S}$ or $\mathrm{A}$; perfluorooctane sulfonate or perfluorooctanoate respectively).

The results of present research were reverse with Hofmeister series. Paterova' et al. (2013) observed completely reversed Hofmeister series and correlative with present results. In presence of $\mathrm{Na}_{2} \mathrm{SO}_{4}$, sonolysis of 1,4-benzoquinone significantly enhanced the rate of decomposition, on the other hand, at same condition sonolysis of hydroquinone was slightly/not enhanced the rate of degradation as shown in Figure 2. In presence of $\mathrm{NaCl}$, sonolysis of 1,4-benzoquinone reduced the rate of degradation reaction that is negative effect observed. On the other hand at the same condition, sonolysis of hydroquinone no effect was found (as shown in Figure 4).

Hydroquinone is a reducing agent that is reversibly oxidizable to quinone. The oxidation potential of hydroquinone at $20^{\circ} \mathrm{C}$ and $\mathrm{pH} 7.03$ is 0.2982 volts. Quinones are suggested to be a dominant redox-active moiety within natural organic matter (Nurmi \& Paul 2002) and humic substances (Scott et al. 1998). Electron transfer to quinones can be expected to lead to an increase in semiquinone radical intermediates as well as hydroquinone Figure 6 . Figure 5 shows the time dependence of 1,4-benzoquinone sonication in the absence and presence of different concentration of $\mathrm{Na}_{2} \mathrm{SO}_{4}$. It was observed that 1,4-benzoquinone was degraded under argon 


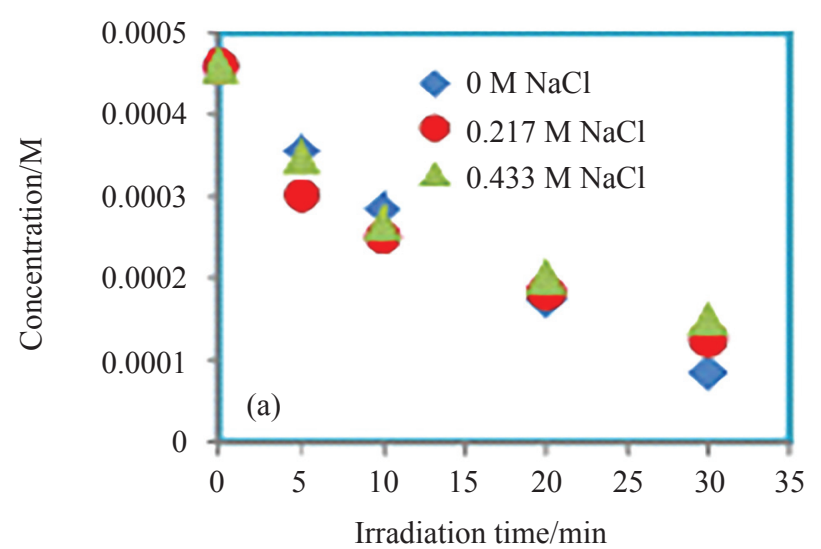

(a)

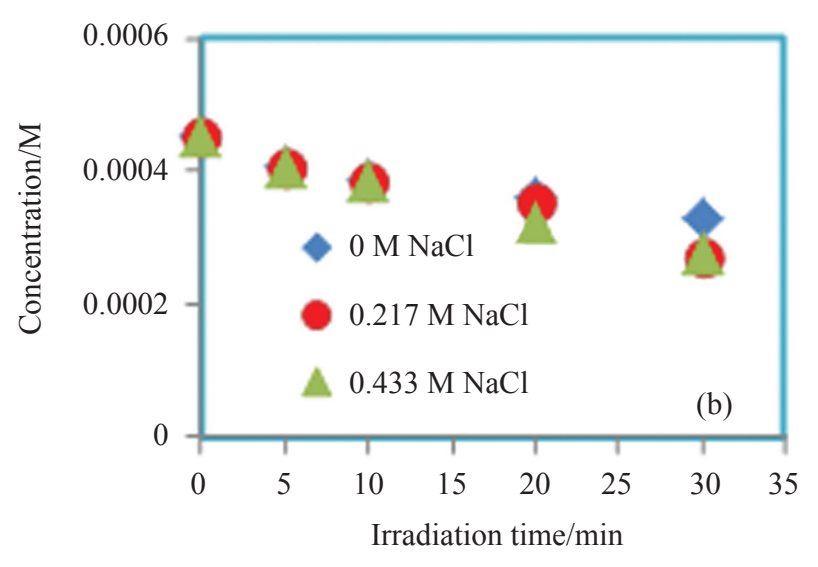

(b)

FIGURE 4. Sonochemical degradation of a) 1,4-benzoquinone and b) hydroquinone in absence and presence of $\mathrm{NaCl}$.

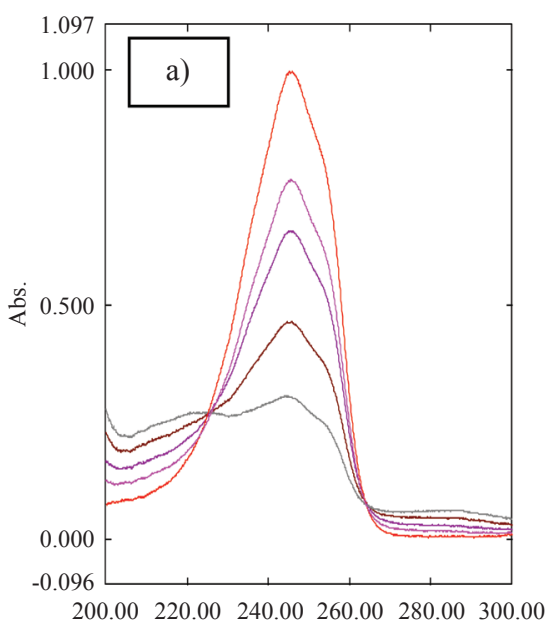

$\mathrm{nm}$

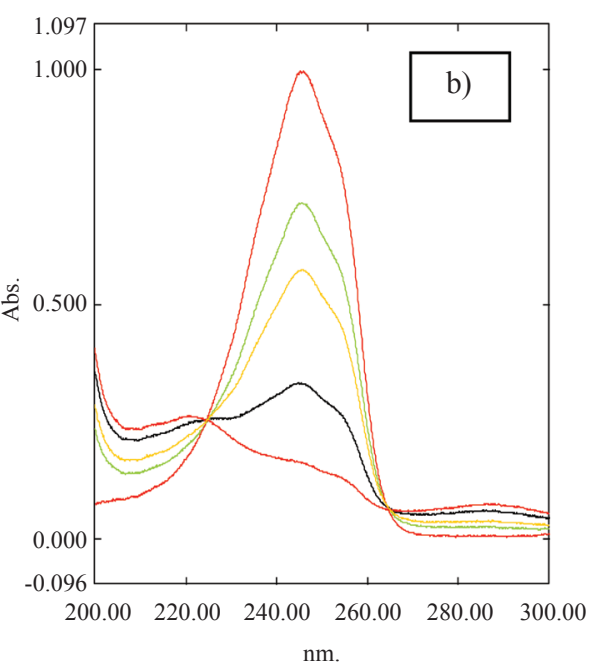

$\mathrm{nm}$.

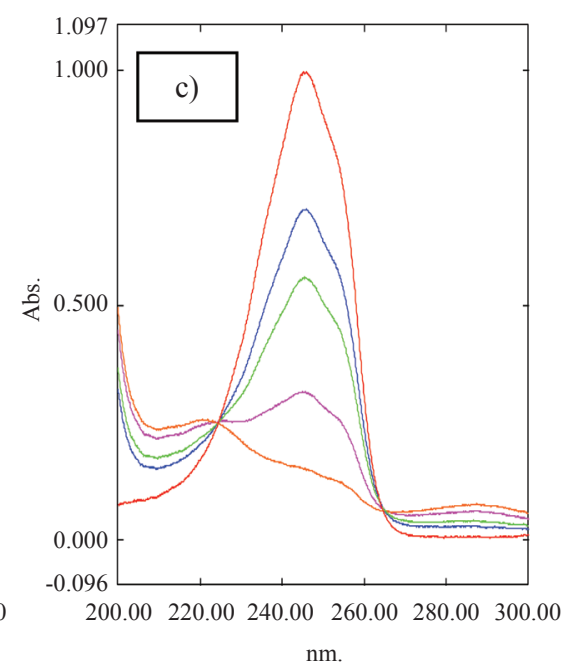

$\mathrm{nm}$.

Figure 5. Time dependence of 1,4-benzoquinone sonication, isosbestic points were observed inthe absence a), in the presence of $0.217 \mathrm{M} \mathrm{b}$ ) and $0.433 \mathrm{M} \mathrm{c}$ ) $\mathrm{Na} \mathrm{SO}_{2}$.

atmosphere due to influence of sonolysis. It can be seen that the absorption peaks corresponding to 1,4-benzoquinone at around $245.7 \mathrm{~nm}$ was gradually decreased. In Figure 5, two isosbestic points were also observed at $225.6 \mathrm{~nm}$ and 264.5 $\mathrm{nm}$, indicating that 1,4-benzoquinone certainly reduced to form hydroquinone and other compounds.

Zhao et al. (2010) studied on enhanced oxidation of 4-chlorophenol using sulfate radicals initiated from zerovalent and peroxydisulfate at ambient temperature and found sulfate radical anion as the dominant active species was responsible for the oxidation of 4-chlorophenol in the ZVI-PDS system, mechanism adopted as Equation (5).

$$
\mathrm{SO}_{4}^{-}+\mathrm{H}_{2} \mathrm{O} \rightarrow \mathrm{HSO}_{4}^{-}+\mathrm{OH}
$$

\section{INTERMEDIATES}

In sonolysis of 1,4-benzoquinone and hydroquinone intermediate was detected at retention time (R.T.) $3.4 \mathrm{~min}$ in absence and presence of different concentrations of $\mathrm{Na}_{2} \mathrm{SO}_{4}$ and $\mathrm{NaCl}$. Another intermediate was detected at retention time $10 \mathrm{~min}$ only for hydroquinone sonolysis.<smiles>O=C1C=CC(=O)C=C1</smiles>

FIGURE 6. Reduction of 1,4-benzoquinone to the intermediate semiquinone radical and furtherreduction to hydroquinone.

Figure 7 shows the formation of intermediate at R.T. = $10.00 \mathrm{~min}$ for sonication of hydroquinone in absence and presence of different concentration of $\mathrm{Na}_{2} \mathrm{SO}_{4}$. The highest amount was produced in absence of $\mathrm{Na}_{2} \mathrm{SO}_{4}$ and lowest was in presence of $0.433 \mathrm{M} \mathrm{Na}_{2} \mathrm{SO}_{4}$. It may 1,4-benzoquinone and quantitatively measurement as shown in Figure 8. The maximum 1,4-benzoquinone was produced $15.73 \mu \mathrm{M}$ in the absence of $\mathrm{Na}_{2} \mathrm{SO}_{4}$. 


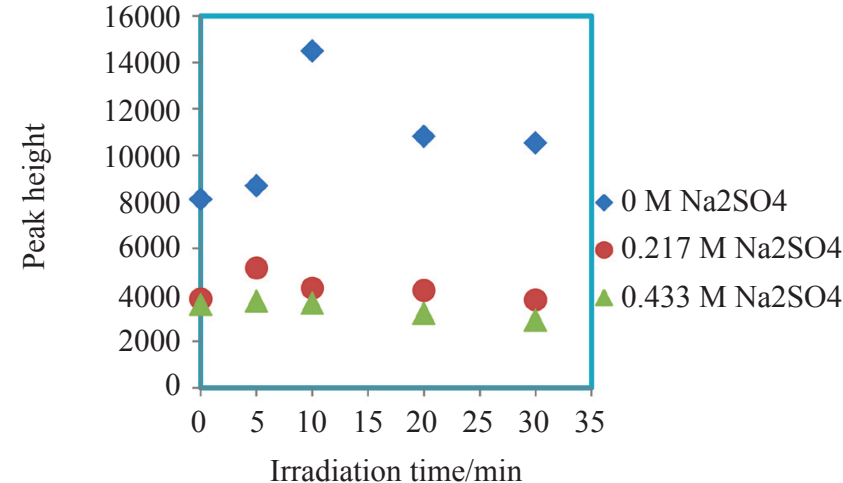

FIGURE 7. Formation of intermediate at R.T. $=10.00$ for sonication of hydroquinone in presence of different concentration of $\mathrm{Na} \mathrm{SO}$

Figure 9 shows the formation of intermediate at R.T. $=3.4 \approx 3.7$ for sonication of a) 1,4-benzoquinone, and $\mathrm{b}$ ) hydroquinone in the absence and presence of different concentration of $\mathrm{Na}_{2} \mathrm{SO}_{4}$. The highest amount of intermediate was produced in the presence of $0.217 \mathrm{M} \mathrm{Na}_{2} \mathrm{SO}_{4}$. Also,

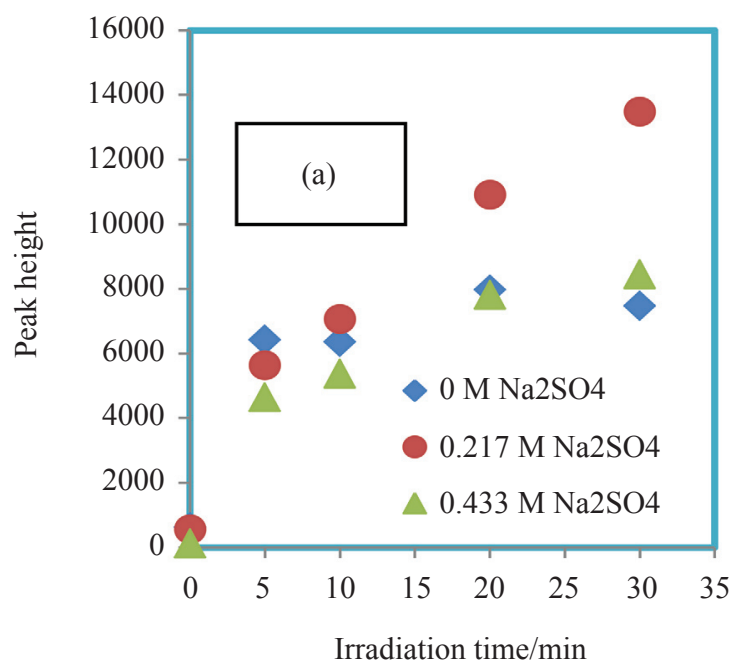

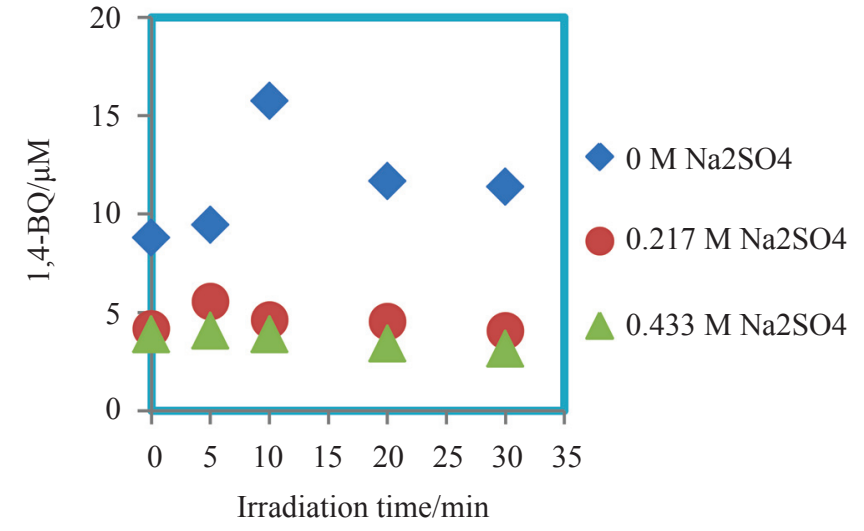

FIGURE 8. Formation of 1,4-benzoquinone in hydroquinone solution at different concentration of $\mathrm{Na} \mathrm{SO}_{4}$ (Peak height).

experimentally same intermediates were detected in the presence of different concentrations of $\mathrm{NaCl}$. Figure 10 is indicating the reaction mechanism of 1,4-benzoquinone and hydroquinone.

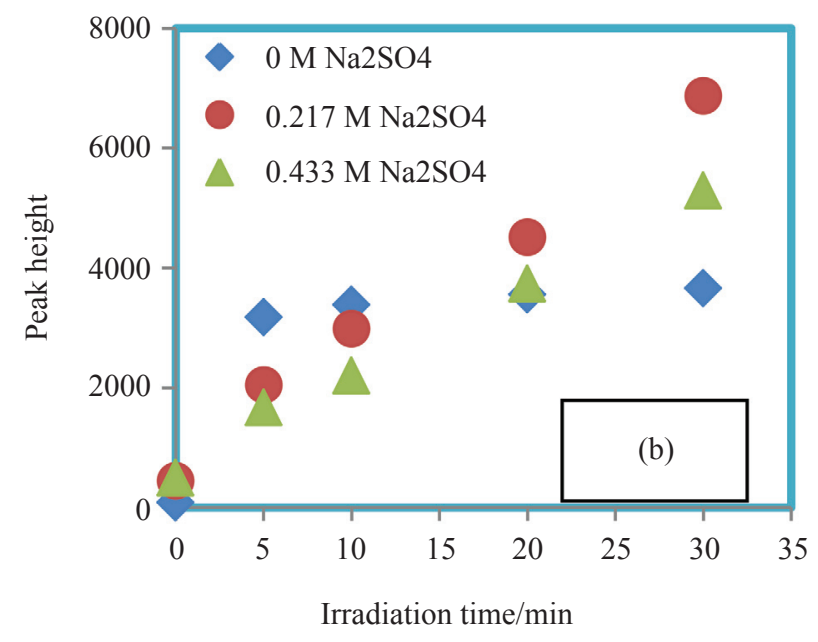

FIGURE 9. Formation of intermediate at R.T. $=3.4 \approx 3.7$ for sonication of a) 1,4-benzoquinoneand b) hydroquinone in the absence and presence of different concentration of $\mathrm{Na}_{2} \mathrm{SO}_{4}$.

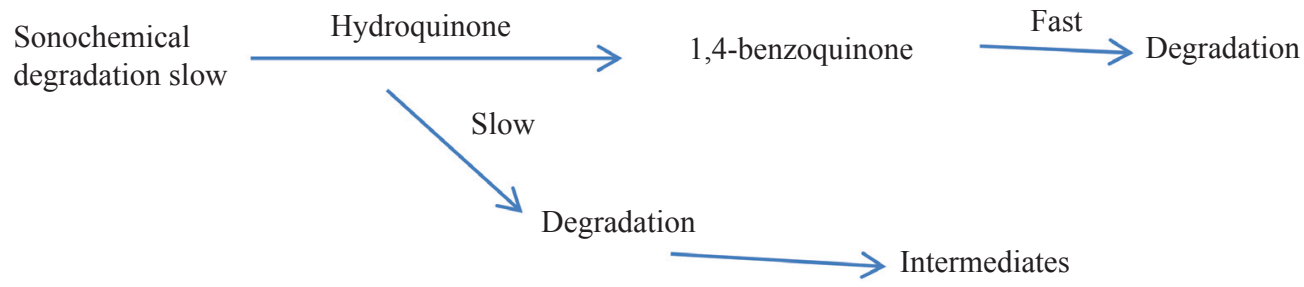

Sonochemical degradation 10.6 times faster

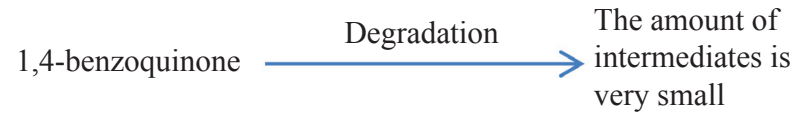

FIGURE 10. Reaction mechanism of 1,4-benzoquinone and hydroquinone 
CONCLUSIONS

The effects of $\mathrm{Na}_{2} \mathrm{SO}_{4}$ and $\mathrm{NaCl}$ on the sonochemical degradation of 1,4-benzoquinone and hydroquinone were investigated by using $200 \mathrm{kHz}$ sonicator. In absence and presence of $\mathrm{Na}_{2} \mathrm{SO}_{4}$ initial rates of sonochemical degradation were significantly increased in the order 1,4-benzoquinone > hydroquinone. Based on the experimental results, in absence of $\mathrm{Na}_{2} \mathrm{SO}_{4}$ 1,4-benzoquinone sonochemical degradation rate was 4.5 times higher than hydroquinone, whereas in presence of $0.433 \mathrm{M} \mathrm{Na}_{2} \mathrm{SO}_{4}$ at same condition 1,4benzoquinone reaction rate was increased 10.6 times higher than hydroquinone. On the other hand, in presence of $\mathrm{NaCl}$ initial rate of sonochemical degradation of 1,4-benzoquinone and hydroquinone was different. In the presence of different concentrations of $\mathrm{NaCl}$ the initial rate of sonochemical degradation of 1,4-benzoquinone was reduced. Also, in presence of same concentration of $\mathrm{NaCl}$ the initial rate of degradation of hydroquinone was no/very little effect.

\section{ACKNOWLEDGEMENTS}

We acknowledge JSPS for financial support as postdoctoral fellowship. Kenji Okitsu acknowledges the support of JSPS KAKENHI Grant Number 25-03048 and 25340072.

\section{REFERENCES}

Anotai, J., Ming-Chun, L. \& Parichat, C. 2006. Kinetics of aniline degradation by Fenton and electro-Fenton processes. Water Research 40(9): 1841-1847.

Ashokkumar, M., 2008. Advanced wet-chemical synthetic approaches to inorganic nanostructures, Transworld Research Network: Kerala, 107-131.

Ashokkumar, M. \& Grieser, F. $2004 . \quad$ Single bubble sonoluminescence-A chemist's overview. Chem. Phys. Chem 5: 439-448.

Bandala, E. R., Miguel, A. P., Dionysios, D.D., Silvia, G., Javier, G. \& Diana, M. 2007. Degradation of 2, 4-dichlorophenoxyacetic acid (2, 4-D) using cobaltperoxymonosulfate in Fenton-like process. Journal of Photochemistry and Photobiology A: Chemistry 186(2-3): 357-363.

Berlan, J., Trabelsi, F., Delmas, H., Wilhelm, A. M. \& Petrignani, J. F. 1994. Oxidative degradation of phenol in aqueous media using ultrasound. Ultrasonics Sonochemistry 1(2): S97-S102.

Bilimoria, M. H. 1975. The detection of mutagenic activity of chemicals and tobacco smoke in a bacterial system. Mutation Research/Environmental Mutagenesis and Related Subjects 31(5): 328.

Bailey, S. I. \& Ritchie, I. M. 1985. A cyclic voltammetric study of the aqueous electrochemistry of some quinones. Electrochimica Acta 30(1): 3-12.

Cheng, J., Chad, D. V., Hyunwoong, P., Brian, T. M. \& Michael, R. H. 2009. Sonochemical degradation of perfluorooctane sulfonate (PFOS) and perfluorooctanoate
(PFOA) in groundwater: kinetic effects of matrix inorganics. Environmental Science \& Technology 44(1): 445-450.

Dükkanc1, M. \& Gündüz, G. 2006. Ultrasonic degradation of oxalic acid in aqueous solutions. Ultrasonics Sonochemistry 13(6): 517-522.

Entezari, M. H., Christian, P. \& Pierre, D. 2003. Sonochemical degradation of phenol in water: a comparison of classical equipment with a new cylindrical reactor. Ultrasonics Sonochemistry 10(2): 103-108.

Fernandez, J., Pichai, M., Albert, R. \& John, K. 2004. Bleaching and photobleaching of Orange II within seconds by the oxone/Co2+ reagent in Fenton-like processes. Applied Catalysis B: Environmental 49(3): 207-215.

Guo, W.-Q., Jie, D., Guang-Li, C., Nan-Qi, R. \& Fu-Yi, C. 2011. Treatability study of using low frequency ultrasonic pretreatment to augment continuous biohydrogen production. International Journal of Hydrogen Energy 36(21): 14180-14185.

Guo, W.-Q., Shan-Shan, Y., Wen-Sheng, X., Xiang-Jing, W. \& Nan-Qi, R. 2013. Minimization of excess sludge production by in-situ activated sludge treatment processes-A comprehensive review. Biotechnology Advances 31(8): 1386-1396.

Hori, H., Ari, Y., Etsuko, H., Sachi, T., Nobuyoshi, Y., Shuzo, K., Hiroshi, K. \& Ryuichi, A. 2005. Efficient decomposition of environmentally persistent perfluorocarboxylic acids by use of persulfate as a photochemical oxidant. Environmental Science \& Technology 39(7): 2383-2388.

He, J., Tian, W., Guangming, Z. \& Jing, Y. 2011. Ultrasonic reduction of excess sludge from activated sludge system: Energy efficiency improvement via operation optimization. Ultrasonics Sonochemistry 18(1): 99103.

Henglein, A. \& Kormann, C. 1985. Scavenging of OH radicals produced in the sonolysis of water. International Journal of Radiation Biology and Related Studies in Physics, Chemistry and Medicine 48(2): 251-258.

Jyothi, K. P., Suguna, Y. \& Yesodharan, E. P. 2014. Ultrasound (US), Ultraviolet light (UV) and combination (US+ UV) assisted semiconductor catalysed degradation of organic pollutants in water: Oscillation in the concentration of hydrogen peroxide formed in situ. Ultrasonics Sonochemistry 21(5): 1787-1796.

Joseph, C. G., Gianluca, L. P., Awang, B., Yun, H. T.-Y. \& Duduku, K. 2011. Operating parameters and synergistic effects of combining ultrasound and ultraviolet irradiation in the degradation of 2, 4, 6-trichlorophenol. Desalination 276(1-3): 303-309.

Joschek, H-I. \& Sidney, I. M. 1966. Photooxidation of phenol, cresols, and dihydroxybenzenes1, 2. Journal of the American Chemical Society 88(14): 3273-3281.

Kawamukai, M. 2002. Biosynthesis, bioproduction and novel roles of ubiquinone. Journal of Bioscience and Bioengineering 94(6): 511-517. 
Khachatryan, L., Julien, A., Zofia, M. \& Barry, D. 2006. Formation of cyclopentadienyl radical from the gasphase pyrolysis of hydroquinone, catechol, and phenol. Environmental Science \& Technology 40(16): 50715076.

Lim, M., Younggyu, S. \& Jeehyeong, K. 2014. The effects of hydrogen peroxide on the sonochemical degradation of phenol and bisphenol A. Ultrasonics Sonochemistry 21(6): 1976-1981.

Leighton, P. A. \& George, S. F. 1929. The photochemical decomposition of benzoquinone in water and in alcohol. Journal of the American Chemical Society 51(12): 3549-3559.

Lente, G. \& James, H. E. 2004. Photoreduction of 2, 6-dichloroquinone in aqueous solution: Use of a diode array spectrophotometer concurrently to drive and detect a photochemical reaction. Journal of Photochemistry and Photobiology A: Chemistry 163(1-2): 249-258.

Lee, M-R., Jsuey, J., Wei-Shin, H. \& Bao-Huey, H. 1999. Determination of pyrolysis products of smoked methamphetamine mixed with tobacco by tandem mass spectrometry. Journal of Analytical Toxicology 23(1): 41-45.

Leanderson, P. \& Christer, T. 1992. Cigarette smoke-induced DNA damage in cultured human lung cells: role of hydroxyl radicals and endonuclease activation. Chemicobiological Interactions 81(1-2): 197-208.

Ledesma, E. B., Nathan, D. M., Alyssa, K. S. \& Mary, J. W. 2002. An experimental study on the thermal decomposition of catechol. Proceedings of the Combustion Institute 29(2): 2299-2306.

Makino, K., Magdi, M. M. \& Peter, R. 1983. Chemical effects of ultrasound on aqueous solutions. Formation of hydroxyl radicals and hydrogen atoms. The Journal of Physical Chemistry. 87(8): 1369-1377.

Mallakpour, S., Maryam, M. \& Sahar, R. 2014. Applications of ultrasound for modification of zinc oxide and fabrication of optically active poly (amide-imide)/zinc oxide bionanocomposites. Designed Monomers and Polymers 17(4): 364-371.

Marsh, N. D., Elmer, B. L., Alyssa, K. S. \& Mary J. W. 2004. Yields of Polycyclic Aromatic Hydrocarbons from the Pyrolysis of Catechol [ortho-Dihydroxybenzene]: Temperature and Residence Time Effects. Energy \& Fuels 18(1): 209-217.

Mason, T. J. 1991. Practical Sonochemistry: User's Guide to Applications in Chemistry and Chemical Engineering. Ellis Horwood.

Moret, E. E., Mark, de-B., Hans, W. H., Jan, P. T., Lambert, H. M. J., Joost, J. M. H., Reinoud, J. D., Willem, V. \& David, N. R. 1996. In vivo activity and hydrophobicity of cytostatic aziridinyl quinones. Journal of Medicinal Chemistry 39(3): 720-728.

Nanzai, B., Kenji, O., Norimichi, T., Hiroshi, B. \& Yasuaki, M. 2008. Sonochemical degradation of various monocyclic aromatic compounds: Relation between hydrophobicities of organic compounds and the decomposition rates. Ultrasonics Sonochemistry 15(4): 478-483.
Nurmi, J. T. \& Paul, G. T. 2002. Electrochemical properties of natural organic matter (NOM), fractions of NOM, and model biogeochemical electron shuttles. Environmental Science \& Technology 36(4): 617-624.

Okamura, M. Y., Paddock, M. L., Graige, M. S. \& Feher, G. 2000. Proton and electron transfer in bacterial reaction centers. Biochimica et Biophysica Acta (BBA)Bioenergetics 1458(1): 148-163.

Okitsu, K., Akihiko, Y., Shuji, T., Hiroshige, M., Yoshihiro, Y. \& Youngeok, Y. 2002. Sonolytic control of rate of gold (III) reduction and size of formed gold nanoparticles: relation between reduction rates and sizes of formed nanoparticles. Bulletin of the Chemical Society of Japan 75(10): 2289-2296.

Petrier, C., Marie-Francoise, L., Anne, F., Abdallah, B., Bernard, D., Viviane, R. \& Nicolas, G. 1994. Sonochemical degradation of phenol in dilute aqueous solutions: comparison of the reaction rates at 20 and $487 \mathrm{kHz}$. The Journal of Physical Chemistry 98(41): 10514-10520.

Patnaik, P. 2007. A Comprehensive Guide to the Hazardous Properties of Chemical Substances. John Wiley \& Sons.

Paterová, J., Kelvin, B. R., Jan, H., Yadagiri, K., Halil, I. O., Wenshe, R. L., Christian, H., Paul, S. C. \& Pavel, J. 2013. Reversal of the Hofmeister series: specific ion effects on peptides. The Journal of Physical Chemistry $B$ 117(27): 8150-8158.

Rosenfeldt, E. J. \& Karl, G. L. 2004. Degradation of endocrine disrupting chemicals bisphenol A, ethinyl estradiol, and estradiol during UV photolysis and advanced oxidation processes. Environmental Science \& Technology 38(20): 5476-5483.

Riesz, P., Berdahl, D. \& Christman, C. L. 1985. Free radical generation by ultrasound in aqueous and nonaqueous solutions. Environmental Health Perspectives 64: 233252.

Rokhina, E. V., Katerina, M., Manu, L., Elena, A. G., Henk, V. A. \& Jurate, V. 2013. Ultrasound-assisted $\mathrm{MnO}_{2}$ catalyzed homolysis of peracetic acid for phenol degradation: The assessment of process chemistry and kinetics. Chemical Engineering Journal 221: 476-486.

Spanggord, R. J., David, Y. \& Theodore, M. 2000. Kinetics of aminodinitrotoluene oxidations with ozone and hydroxyl radical. Environmental Science \& Technology 34(3): 450-454.

Saccani, G., Bernasconi, M. \& Antonelli, M. 2014. Optimization of low energy sonication treatment for granular activated carbon colonizing biomass assessment. Environmental Technology 35(7): 851-858.

Sakakura, M. \& Mitsuo, T. 2012. Improved sonolytic hydrolysis of peptides in aqueous solution with addition of 1, 4-benzenedithiol. Ultrasonics Sonochemistry 19(3): 615-620.

Serpone, N., Terzian, R., Colarusso, P., Minero, C., Pelizzetti, E. \& Hidaka, H. 1993. Sonochemical oxidation of phenol and three of its intermediate products in aqueous 
media: catechol, hydroquinone, and benzoquinone. Kinetic and mechanistic aspects. Research on Chemical Intermediates 18(2): 183-202.

Spyroudis, S. 2000. Hydroquinones: synthesis and reactivity. Molecules (5): 1291-1330.

Sakai, T. \& Masayuki, H. 1976. Thermal decarbonylation of catechol, hydroquinone and resolsinol. Chemistry Letters 5(11): 1153-1156.

Scott, D. T., Diane, M. M., Elizabeth, L. B-H., Sarah, E. K. \& Derek, R. L. 1998. Quinone moieties act as electron acceptors in the reduction of humic substances by humics-reducing microorganisms. Environmental Science \& Technology 32(19): 2984-2989.

Topping, D. C., Lisa, G. B., John, L. O’D. \& Caroline, E. J. 2007. Hydroquinone: acute and subchronic toxicity studies with emphasis on neurobehavioral and nephrotoxic effects. Food and Chemical Toxicology 45(1): 70-78.

Torres-Palma, R.A., Nieto, J.I., Combet, E., Petrier, C. \& Pulgarin, C., 2010. An innovative ultrasound, $\mathrm{Fe} 2+$ and $\mathrm{TiO} 2$ photoassisted process for bisphenol a mineralization. Water Research 44(7): 2245-2252.

Uddin, M. H., Ben, N. \& Kenji, O. 2016. Effects of $\mathrm{Na}_{2} \mathrm{SO}_{4}$ or $\mathrm{NaCl}$ on sonochemical degradation of phenolic compounds in an aqueous solution under Ar: Positive and negative effects induced by the presence of salts. Ultrasonics Sonochemistry 28: 144-149.

Verma, A., Harmanpreet, K. \& Divya, D. 2013. Photocatalytic, sonolytic and sonophotocatalytic degradation of 4-chloro-2-nitro phenol. Archives of Environmental Protection 39(2): 17-28.

Visser, R., Harbers, A. A. M., Hovestad, A. \& Stevens, T. W. 1985. Identification of organic compounds in waste water of wood gasifiers with capillary gas chromatography. In Proceedings of the 6th International Symposium on Capillary Chromatography, 281-287.

Veith, G. D., Austin, N. M. \& Morris, R. T. 1979. A rapid method for estimating $\log \mathrm{P}$ for organic chemicals. Water Research 13(1): 43-47.

Waldemer, R. H., Paul, G. T., Richard, L. J. \& James, T. N. 2007. Oxidation of chlorinated ethenes by heat-activated persulfate: kinetics and products. Environmental Science \& Technology 41(3): 1010-1015.

Wang, R.-C. \& Chih-Wen, Y. 2013. Phenol degradation under visible light irradiation in the continuous system of photocatalysis and sonolysis. Ultrasonics Sonochemistry 20(1): 553-564.
Yang, S.-S., Wan-Qian, G., Guang-Li, C., He-Shan, Z. \& Ren, N. Q. 2012. Simultaneous waste activated sludge disintegration and biological hydrogen production using an ozone/ultrasound pretreatment. Bioresource Technology 124: 347-354.

Yang, S.-S., Wan-Qian, G, Zhao-Hui, M., Xian-Jiao, Z., XiaoChi, F., He-Shan, Z., Bo, L., Nan-Qi, R. \& Ya-Shan, C. 2013. Characterizing the fluorescent products of waste activated sludge in dissolved organic matter following ultrasound assisted ozone pretreatments. Bioresource Technology 131: 560-563.

Yim, B., Youngeok, Y., \& Yasuaki, M. 2003. Sonolysis of alkylphenols in aqueous solution with Fe (II) and Fe (III). Chemosphere 50(8): 1015-1023.

Zhang, K., Naiyun, G., Yang, D., Tsair, F. L., Yan, M., Lei, L. \& Minghao, S. 2011. Degradation of bisphenol-A using ultrasonic irradiation assisted by low-concentration hydrogen peroxide. Journal of Environmental Sciences 23(1): 31-36.

Zhao, J., Yaobin, Z., Xie, Q. \& Shuo, C. 2010. Enhanced oxidation of 4-chlorophenol using sulfate radicals generated from zero-valent iron and peroxydisulfate at ambient temperature. Separation and Purification Technology 71(3): 302-307.

*Md. Helal Uddin

Department of Applied Chemistry \&

Chemical Engineering

Faculty of Applied Science and Technology

Islamic University, Kushtia-7003, Bangladesh.

\section{Kenji Okitsu}

Department of Materials Science

Graduate School of Engineering

Osaka Prefecture University

1-1 Gakuen-cho, Naka-ku, Sakai, Osaka 599-8531, Japan.

*Corresponding author; email: uddindrhelal@gmail.com

Received date: $4^{\text {th }}$ August 2017

Accepted date: $9^{\text {th }}$ April 2018

Online First date: $1^{\text {st }}$ September 2018

Published date: $31^{\text {st }}$ October 2018 